Check for updates

Cite this: J. Mater. Chem. C, 2020 8, 11922

Received 27th April 2020,

Accepted 31st July 2020

DOI: $10.1039 / \mathrm{d0tc02050h}$

rsc.li/materials-c

\title{
Upconversion luminescence in cellulose composites (fibres and paper) modified with lanthanide-doped $\mathrm{SrF}_{2}$ nanoparticles $\dagger$
}

\author{
Agata Szczeszak, (D)*a Małgorzata Skwierczyńska, (D) a Dominika Przybylska, (D) a \\ Marcin Runowski, ${ }^{a}$ Emilia Śmiechowicz, ${ }^{b}$ Aleksandra Erdman, (iD c \\ Olena Ivashchenko, (D) d Tomasz Grzyb, (D) ${ }^{a}$ Stefan Lis, (D) a Piotr Kulpiński ${ }^{\mathrm{b}}$ and \\ Konrad Olejnikc
}

\begin{abstract}
The use of functional nanomaterials and their combination with organic polymers leads to the formation of advanced composites and hybrid inorganic-organic systems having unique properties. The use of such materials as anti-counterfeiting agents (invisible under ambient conditions) is crucial for modern security systems and for further identification of labelled items and documents in various industrial applications. Here, the fabrication of functional paper by in situ incorporation of luminescent cellulose fibres into its structure, during the formation of paper pulp, is shown. In order to produce luminescent fibres, an in situ modification is made during the spinning process, using lanthanide-doped upconverting nanoparticles $\left(\mathrm{SrF}_{2}: \mathrm{Yb}^{3+}, \mathrm{Er}^{3+}\right)$. At first glance (in daylight), the functionalized paper cannot be distinguished from its unmodified form. However, when exposed to invisible near-infrared laser light (975 nm), bright green illumination appears. The modified paper preserves good mechanical durability, which is important for its potential for further processing in documents and other commercially available forms. Protecting documents and various materials with this kind of paper may open new horizons in materials engineering, forensics, and other industrial applications.
\end{abstract}

\section{Introduction}

Nowadays, functionalized bulk, micro-, and nano-sized materials are extensively studied due to their unique properties, the combination of several functionalities in one system (multifunctional capabilities), the possibility of manipulation on a sub-micro-scale, high spatial resolution, and access to previously inaccessible smallsized regions. ${ }^{1-5}$ Currently, interest in the formation of lanthanidedoped nanomaterials is growing, almost exponentially. ${ }^{6-10}$ This is mainly due to their favourable optical, electronic, magnetic, and catalytic properties. ${ }^{10-13}$ Inorganic materials doped with $\mathrm{Ln}^{3+}$ ions

\footnotetext{
${ }^{a}$ Adam Mickiewicz University in Poznań, Faculty of Chemistry, Department of Rare Earths, Uniwersytetu Poznańskiego 8, 61-614 Poznań, Poland.

E-mail: agata_is@amu.edu.pl

${ }^{b}$ Lodz University of Technology, Faculty of Material Technologies and Textile Design, Department of Mechanical Engineering, Informatics and Chemistry of Polymer Materials, Żeromskiego 116, 90-924 Lodz, Poland

Lodz University of Technology, Centre of Papermaking and Printing, Wólczańska 223, 90-924 Lodz, Poland

${ }^{d}$ NanoBioMedical Centre, Adam Mickiewicz University in Poznan, Wszechnicy Piastowskiej 3, 61-614 Poznań, Poland

$\dagger$ Electronic supplementary information (ESI) available. See DOI: 10.1039/ dotc02050h
}

usually exhibit resistance to photobleaching, high-temperature and high-pressure treatment, stability of the $3+$ oxidation state, and low cytotoxicity, etc. ${ }^{11-18}$

In the case of optical characteristics, lanthanide ions (mainly $\mathrm{Ln}^{3+}$ ) may exhibit multi-range luminescence (i.e. down-shifting) and upconversion luminescence in UV-Vis-NIR (ultravioletvisible-near-infrared) spectral regions, long luminescence lifetimes, and large spectral shifts of the emission compared to excitation, etc. ${ }^{12-14,19,20}$ Upconversion is a non-linear optical process, i.e. the emission of anti-Stokes radiation, based on the absorption of two or more photons with lower energy and, then, emission of one photon with higher energy. ${ }^{15,21,22}$ Upconverting phosphors are worthy of particular attention because they allow the observation of visible light activated with lower energy NIR radiation, enabling "invisible activation of the visible effect," which is very useful in various applications, especially in the field of advanced document protection and modern security systems. ${ }^{13}$ Two examples related to this field, in which luminescence (UV-excited) and upconversion (NIR-excited) luminescence of $\mathrm{Ln}^{3+}$-based materials can be used, include (I) luminescent dactyloscopic powders for advanced fingerprint detection and (II) luminescent inks working as anti-counterfeiting agents for banknote protection. ${ }^{23,24}$ 
In recent years, scientists have been working on the synthesis of a wide range of nanomodifiers for materials with various unique properties, providing innovative and highly functional composites. $^{25-29}$ One of the continually growing areas of science is the development of high-quality nanophosphors, which can be incorporated into some polymer-based materials, such as fibres or paper. The composites obtained in this way can be used to protect paper (documents), banknotes, or textiles. ${ }^{13,23,24}$

Erdman et al. obtained UV-sensitive, optically active cellulose fibres containing $0.5 \% \mathrm{w} / \mathrm{w} \mathrm{Sr}_{2} \mathrm{CeO}_{4}, \mathrm{Gd}_{2} \mathrm{O}_{3} \mathrm{~F}_{6}: 5 \% \mathrm{Eu}^{3+}$, or $\mathrm{CeF}_{3}: 5 \% \mathrm{~Tb}^{3+}$ nanoparticles (NPs), exhibiting blue, red, and green emission, respectively. ${ }^{30}$ The obtained fibres show high photoluminescence intensity under UV light irradiation, and the character of the compounds yields fibres that emit light of different colours. Li et al. obtained a new type of luminescent fibres, working as optical temperature sensors, based on the detection of fluorescence intensity ratio (FIR). ${ }^{31}$ The fibres contained upconverting NPs $\left(\mathrm{NaYF}_{4}: \mathrm{Er}^{3+}, \mathrm{Yb}^{3+}\right)$ working as optical temperature sensors. NPs were embedded in optical multi-mode quartz graded fibre, using fibre fusion technology. The presented results showed that the fabricated sensor has good sensing performance in the range of 40 to $80{ }^{\circ} \mathrm{C}$. Reproducibility of the sensor's FIR parameter, confirmed during heating-cooling cycles, indicates good stability and reliability, which proves rationality for the construction of a luminescence fibre sensor. Such fibres can be used as temperature sensors in scientific applications, industry, and other areas.

Luminescent compounds and fibres, which provide new or additional functionalities, are also a focus of scientists involved in the development of new paper or paper-based composite products for special applications (e.g. authentication purposes, control of information circulation, storage of hidden information). Strong interest in these products is not simply due to the desired luminescent properties. One field of research is connected with surface modification of paper. Zuxue et al. obtained magnetic paper by coating its surface with Tb-doped germanium borosilicate glass. ${ }^{32}$ The glass modifier was ground into small particles and modified with graphene oxide by electrostatic interaction. This type of paper can be used for information storage or industrial security. Research shows that magnetic paper has been successfully produced, and its mechanical properties were also improved by the performed modification. Another possibility for paper functionalization is to introduce other types of fibres, with different properties, into the paper structure. Shi and Wang obtained a paper composite with carbon fibres. ${ }^{33}$ The modification enhanced the mechanical properties of the paper and had a negligible effect on the electrical properties. Chang et al. obtained polyaniline and zirconium phenylphosphonate-modified cellulose fibres, which may be used for flexible paper-based electrodes. ${ }^{34}$

Nevertheless, modification of paper structure with luminescent fibres (containing functional NPs) is one of the most interesting advanced paper applications for document protection and other security purposes. The fibres, being a security agent in paper, can be made of natural or synthetic polymers, while luminescence modification can be done by dying the surface of the fibres or incorporating luminescent material into the polymer mass during the fibre formation process. ${ }^{35,36}$

Luminescent lyocell fibres, obtained earlier by our research group, have many advantages related to their biodegradability because they utilize the same compound present in natural fibres used in paper production, i.e. cellulose. ${ }^{37}$ This means lyocell fibres could have better binding properties. These properties can be further increased by fibre fibrillation during the refining process. Interestingly, fibrillation and partial damage of lyocell fibres during the refining operation does not affect their luminescence properties. Moreover, we obtained paper-containing artificial fibres showing UV-excited luminescence properties, which allows us to estimate fibre orientation on-line production during the paper manufacturing process. ${ }^{38}$ In this work, we show that the presence of luminescent fibres incorporated in paper may have applications other than security, which are of crucial importance from the point of view of the paper production process.

To the best of our knowledge, this is the first report showing the possibility of manufacturing upconverting paper, protected by gently incorporated fibres and functionalized with NIR-excited luminescent NPs, exhibiting the upconversion phenomenon. The presented article discusses the paper composite production with special and highly efficient luminescence properties, obtained by incorporating lyocell fibres with upconversion properties into the paper mass.

\section{Experimental}

\section{Materials}

Rare earth (RE) oxides, $\mathrm{Er}_{2} \mathrm{O}_{3}$ and $\mathrm{Yb}_{2} \mathrm{O}_{3}$ (99.99\%, Stanford Materials, United States), were dissolved separately in hydrochloric acid (HCl; ultra-pure, 37\%, Sigma-Aldrich, Poland) to obtain the respective $\mathrm{RE}$ chloride solutions. Ammonium fluoride $\left(\mathrm{NH}_{4} \mathrm{~F}\right.$; $\geq 98 \%$, Sigma-Aldrich, Poland) was used as the source of fluoride ions. Strontium chloride hexahydrate $\left(\mathrm{SrCl}_{2} \cdot 6 \mathrm{H}_{2} \mathrm{O} ; \geq 99 \%\right.$, SigmaAldrich, Poland) and citric acid trisodium salt dihydrate (97\%, Sigma-Aldrich, Poland) were used as received, without further purification. Deionized water was used for the synthesis.

Cellulose pulp (Rayonier Ltd) containing $98 \mathrm{wt} \%$ of $\alpha$-cellulose, with an average polymerization degree of about $1250 \mathrm{DP}$, and $N$-methylmorpholine $N$-oxide (NMMO), as a $50 \%$ aqueous solution (from Huntsman Holland BV, the Netherlands), were used for the preparation of the spinning dope. The propyl ester of gallic acid (Tenox PG ${ }^{\circledR}$ ) from Aldrich (Gillingham, Dorset, UK) was applied as an antioxidant.

Commercial bleached softwood kraft (BSK) pine pulp was used for laboratory paper sample production. Pulp was obtained from one of the Polish paper mills in the form of sheets with a dryness of about $93.3 \%$. The pulp was disintegrated according to ISO 5263-3:2004 standard and refined in a PFI laboratory mill according to ISO 5264-2:2011.

\section{Apparatus}

X-ray diffraction patterns (XRD) were measured with a Bruker AXS D8 Advance diffractometer in the Bragg-Brentano geometry (6-60 $2 \theta$ range) using $\mathrm{Cu} \mathrm{K} \alpha 1$ radiation $(\lambda=1.5406 \AA)$. The reference data 
were taken from the Inorganic Crystal Structure Database (ICSD). Compositions of the prepared materials were analysed by inductively coupled plasma-optical emission spectrometer (Varian ICPOES VISTA-MPX). Transmission-electron-microscopy (TEM) images were acquired using a FEI Tecnai G2 20 X-TWIN transmission electron microscope and accelerating voltage of $200 \mathrm{kV}$. DLS (dynamic light scattering) and zeta potential measurements were performed using a Malvern Zetasizer Nano ZS instrument. Sample concentration for measurements was $0.25 \mathrm{mg} \mathrm{mL}^{-1}$. Zeta potential was measured at physiological $\mathrm{pH}$. Scanning electron microscope (SEM; FEI Quanta 250 FEG), using an EDAX detector, was used to examine the morphology and distribution of elements via energy dispersive X-ray analysis (EDX) in modified fibres.

Emission spectra were recorded using an Andor Shamrock 500 spectrometer connected to a Peltier-cooled Andor Indus (silicon) CCD (charge-coupled device) camera. A fibre-coupled, solid state diode pumped (SSDP) continuous wave (CW) NIR 975 laser was used as the excitation source. Luminescence decay curves were measured using an Opolette 355LD UVDM tuneable laser (with a repetition rate of $20 \mathrm{~Hz}$ ) and a QuantaMaster $^{\mathrm{TM}} 40$ spectrophotometer using a Hamamatsu R928 photomultiplier detector. An optical microscope, Delta Optical IPOS-810, with a CCD camera was used for imaging cellulose fibres.

To prepare the cellulose solution, a high-efficiency laboratoryscale Ikavisk kneader (IKAVISC kneader type MKD 0.6-H60; IKA-ANALYSENTECHNIK, Heitersheim, Germany) was used. The operating volume of this apparatus is about $300 \mathrm{~mL}$. The system is equipped with temperature sensors, a stirrer, and a torque moment counter (for measurement of torsional moment). These parameters are recorded by a computer. A laboratory-scale spinning machine was used to produce the fibres, which were formed by the dry-wet method, using a spinneret with 18 orifices.

Fluorescence measurements were performed with a confocal laser scanning microscopy system, LSM 780 (Zeiss), equipped with a femtosecond tuneable infrared laser for two-photon excitation. The images were taken in reflection mode, at excitation wavelengths of 980 and $405 \mathrm{~nm}$, using a PlanApochromat $63 \times / 1.40$ oil immersion objective. The fluorescence spectra were recorded in lambda-mode, excitation wavelength $980 \mathrm{~nm}$.

Zwick materials tensile testing machines, type BZ2.5/TN1S (Ulm, Germany) with TestXpert v. 7.1 software, were used as a powerful, flexible, and cost-effective tensile testing solution for fibres. The linear density of the fibers was determined according to ISO 1973:1995 (E), and the conditioned tenacity and elongation at break were measured according to $\mathrm{PN}-85 / \mathrm{P}-$ $04761 / 04$. Laboratory paper sheets of $70 \mathrm{~g} \mathrm{~m}^{-2}$ were formed in a Rapid-Köthen apparatus, according to standard ISO 52692:2004. Samples were, then, conditioned at $23 \pm 1{ }^{\circ} \mathrm{C}$ and $50 \pm$ 2\% RH, according to standard ISO 187:1990.

Paper samples were formed in the laboratory using the Rapid-Köthen apparatus. Surface roughness of the samples was measured according to ISO 8791-2:2013 standard. Air permeability of paper samples was estimated according to ISO 5636-3:2013 standard.

\section{Synthesis of the luminescent NPs}

$\mathrm{SrF}_{2}$ NPs doped with $20 \mathrm{~mol} \% \mathrm{Yb}^{3+}$ and $1 \mathrm{~mol} \% \mathrm{Er}^{3+}$ were synthesized based on our previously reported procedure. ${ }^{39}$ For preparation of $3.5 \mathrm{mmol}$ of product, $2.77 \mathrm{~mL}$ of $1 \mathrm{M} \mathrm{SrCl}_{2}$ and $0.70 \mathrm{~mL}$ of $1 \mathrm{M} \mathrm{YbCl}_{3}$ were mixed with $0.14 \mathrm{~mL}$ of $0.25 \mathrm{M} \mathrm{ErCl}_{3}$ aqueous solutions and were added to $20 \mathrm{~mL}$ of $1 \mathrm{M}$ sodium citrate (NaCit) solution (complexing agent). Then, $5 \mathrm{~mL}$ of 4.20 $\mathrm{M} \mathrm{NH}_{4} \mathrm{~F}$ solution was added to the solution containing $\mathrm{SrCl}_{2}$ and $\mathrm{LnCl}_{3}$ salts. The $\mathrm{pH}$ of the final mixture was adjusted to 7.5. The as-prepared transparent solution was transferred into a $50 \mathrm{~mL}$ Teflon-lined vessel and hydrothermally treated for $12 \mathrm{~h}\left(180{ }^{\circ} \mathrm{C}, 20\right.$ bars) in an externally heated autoclave (Berghof DAB-2). After completion of the reaction, the resulting white precipitate was purified by centrifugation and rinsed several times with water and ethanol. The final product was dispersed in water.

\section{Preparation of the fibres}

In order to obtain NIR-sensitive cellulose fibres, the $\mathrm{SrF}_{2}: 20 \%$ $\mathrm{Yb}^{3+}, 1 \% \mathrm{Er}^{3+}$ NPs, working as upconverting luminescent modifiers, were introduced into the cellulose matrix of the fibres. The following procedure was applied to obtain luminescent cellulose fibres. The $\mathrm{SrF}_{2}: \mathrm{Yb}^{3+}, \mathrm{Er}^{3+}$ NPs were mixed with $50 \%$ NMMO aqueous solution, cellulose pulp, and antioxidant and, subsequently, transferred to an Ikavisk kneader. Modifier was used in sufficient quantity to reach a concentration of about $0.5 \% \mathrm{w} / \mathrm{w}$ of dry cellulose fibres. The cellulose dissolution process was carried out in a kneader until a homogenous spinning dope was obtained. The fibres were spun using the dry-wet method in a laboratory spinning machine with a speed of $10 \mathrm{~m} \mathrm{~min}^{-1}$, as described in previous works. ${ }^{40}$

\section{Preparation of the paper samples}

A series of paper samples containing cellulose fibres modified with $\mathrm{SrF}_{2}: \mathrm{Yb}^{3+}, \mathrm{Er}^{3+} \mathrm{NPs}$ were obtained with the use of a RapidKöthen laboratory machine for paper production, according to ISO 5259-2:2001. Before the final paper was formed, disintegrated, and refined, the paper pulp was mixed for $10 \mathrm{~min}$ in a laboratory mixing device. Luminescent fibres, in $5 \mathrm{~mm}$ long sections ( $\sim 30 \mu \mathrm{m}$ thick), were added to the pulp at this stage to obtain $2 \mathrm{~g}$ of final paper sheets with the following concentrations of lyocell fibres: $0,0.5,1,3,5$, and $10 \%$. After formation, the paper sheets were dried for $10 \mathrm{~min}$ at $100{ }^{\circ} \mathrm{C}$ and conditioned according to ISO 187:1990.

\section{Results and discussion}

The hydrothermal method of synthesis yields luminescent NPs based on $\mathrm{SrF}_{2}$ doped with $20 \%$ of $\mathrm{Yb}^{3+}$ and $1 \% \mathrm{Er}^{3+}$ ions. These NPs were used as fluoride modifiers (FM) introduced into artificial cellulose fibres, giving them luminescence properties. The FMs have the pure cubic structure of the NPs, in accordance with the reference pattern Inorganic Crystal Structure Database ICSD \#40414 (Fig. S1, ESI $\dagger$ ). There are no additional XRD lines; hence, FMs were obtained without any impurities. 
The XRD pattern of the modified fibre also confirmed the presence of FMs in the fibre matrix. Broadening of the reflexes corresponding to the $\mathrm{SrF}_{2}: \mathrm{Yb}^{3+}, \mathrm{Er}^{3+} \mathrm{NPs}$, observed in the XRD pattern (top) for the modified fibres, may be caused by chemicals used during in situ modification of the fibres, as well as by the mechanical stress applied, affecting the surface of NPs (partial amorphization and changes in the coordination environment) and leading to the formation of surface defects and strains in the crystals. According to TEM analysis, FMs have a slightly irregular morphology, as there are NPs with spherical or elongated shape-forming agglomerates (Fig. 1a). The average grain size of the FM NPs, calculated based on the TEM images, is $42 \pm 10 \mathrm{~nm}$ (Fig. 1a inset).

DLS measurements revealed that the hydrodynamic diameter of the FM NPs (in water, room temperature) are predominantly in the range $75-120 \mathrm{~nm}$ (Fig. S2, ESI $\dagger$ ). Based on the results of TEM measurements, FM NPs in water exist as agglomerates of approximately 8-34 NPs (or 2-3 NPs in agglomerate diameter). This result, as well as zeta potential value $(-19.5 \pm 8.1 \mathrm{mV}$; Table $\mathrm{S} 2$, ESI $\dagger)$, indicates that FM is suitable for use (in the modification process of cellulose fibre) in aqueous media from a technological point of view. However, a negative zeta potential $(-20 \mathrm{mV})$ at physiological $\mathrm{pH}$ confirms the stability of NPs as water colloids (Table S1, ESI $\dagger$ ).

The synthesized FMs were introduced into the fibre matrix, neither disturbing the spinning process nor destroying the final form of the fibres. In order to prove the high quality of the modified fibres, the mechanical properties of standard cellulose fibres (spun without any modifier), as well as fibres modified with NPs, were determined. Measurements of conditioned tenacity and elongation at break are shown in Table 1.

Tenacity of the fibres with 5\% FM increased by about $7 \%$, compared to the fibre without FM, which is connected with a
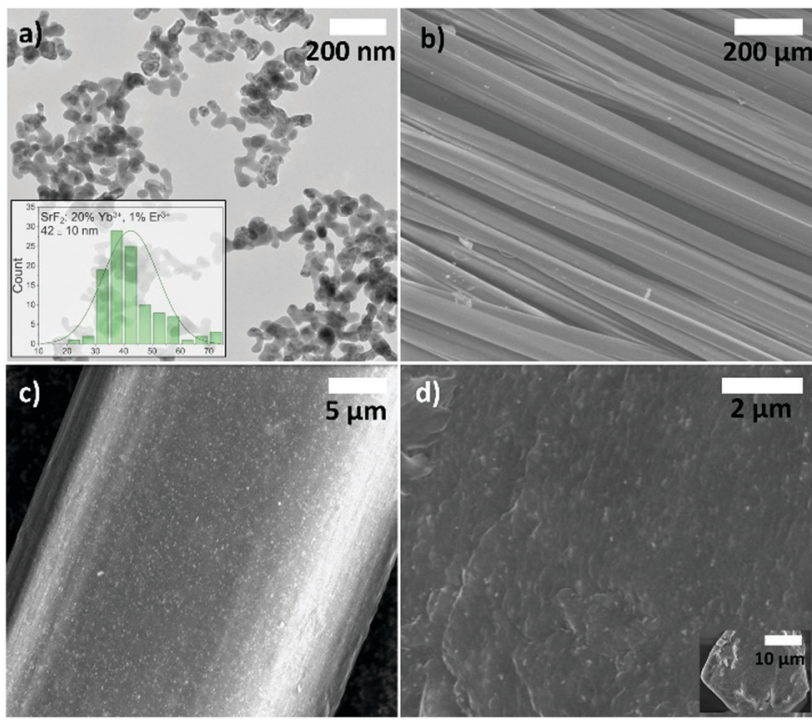

d)

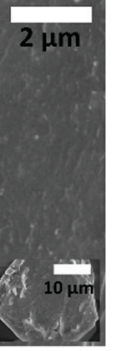

Fig. 1 TEM (transmission electron microscope) (a; inset shows NP size distribution) and SEM images of FMs in the polymer matrix of cellulose fibres ( $b$ and $c$ ) and in the cross section of the cellulose fibre ( $d$; inset shows the cross section of the modified fibre without magnification).
Table 1 The linear density and mechanical properties of the pure and modified fibres

\begin{tabular}{lllll}
\hline & $\begin{array}{l}\text { Linear } \\
\text { density } \\
{[\text { tex }]}\end{array}$ & $\begin{array}{l}\text { Tenacity } \\
{[\mathrm{cN} / \text { tex }]}\end{array}$ & $\begin{array}{l}\text { Standard } \\
\text { deviation } \\
\text { for tenacity }\end{array}$ & $\begin{array}{l}\text { Elongation } \\
\text { at break [\%] }\end{array}$ \\
\hline Fibre without FM & 1.060 & 31.65 & 5.23 & 1.30 \\
Fibre with 5\% FM & 1.252 & 33.88 & 4.97 & 0.55
\end{tabular}

good distribution of the modifier NPs in the polymer matrix of the fibres without any FM aggregations.

The lower value of elongation at the break of the modified fibres has less influence than elasticity of the modified ones. Lower elongation at break values of modified fibres, compared with unmodified ones, have also been reported in the case of the fibres modified with other inorganic luminescent modifiers. ${ }^{41}$

Fibre morphology was analysed using SEM, which enables characterization of the FM NP distribution enclosed in a polymer matrix of cellulose fibres. SEM images and photographs were taken with a camera, showing that the FM (white spots) is well distributed in the whole volume of the fibre polymer matrix (Fig. 1b-d and Fig. S3, ESI $\dagger$ ).

EDX enables identification of particular elements of the FM incorporated in the modified fibres (Fig. 2). The chemical composition in certain areas of the selected fibre indicated the presence of $\mathrm{Sr}, \mathrm{F}, \mathrm{Yb}$, and Er in the polymer matrix of the cellulose fibres. The applied modifier was well distributed in the polymer matrix. Once again, uniform distribution of the FM was demonstrated, without forming any FM aggregates. Such behaviour of the FM ensures uniform luminescent properties over the entire length and volume of the fibres. Additionally, ICP-OES analysis shows that the composition of FM agrees with the stoichiometry of the compound and amount of precursor used (Table S2, ESI $\dagger$ ).

Confocal laser scanning microscopy was used to investigate fluorescence properties of the modified fibre, visualize FM NPs, and estimate their distribution within the cellulose matrix. For this aim, the modified fibre was investigated in reflection mode, at excitation wavelengths of 980 (to visualize FM NPs) and 405 (to visualize cellulose matrix) $\mathrm{nm}$. A laser wavelength of $405 \mathrm{~nm}$ was utilized to excite autofluorescence (native fluorescence) emission of cellulose. ${ }^{42}$ As seen (Fig. 3a), the modified fibre exhibits luminescence after excitation at $980 \mathrm{~nm}$. Multiple bright dots, FM NPs, are homogeneously distributed within the fibre volume. In contrast to FM NPs, the cellulose matrix, excited at $405 \mathrm{~nm}$, emits fluorescence evenly. This approach allowed us to distinguish fluorescence originating from FM NPs and cellulose matrix.

In continuation of this experiment, the fluorescence spectra were recorded in two regions of the modified fibre (Fig. 3b). The spectra are similar, revealing three emission bands centred at approximately 522, 546, and $653 \mathrm{~nm}$. These bands were related to $\mathrm{Er}^{3+}$ ions' emission, indicating ${ }^{2} \mathrm{H}_{11 / 2} \rightarrow{ }^{4} \mathrm{I}_{15 / 2},{ }^{4} \mathrm{~S}_{3 / 2} \rightarrow{ }^{4} \mathrm{I}_{15 / 2}$, and ${ }^{4} \mathrm{~F}_{9 / 2} \rightarrow{ }^{4} \mathrm{I}_{15 / 2}$ transitions.

In summary, the results of confocal laser scanning microscopy measurements demonstrated green emission of modified 

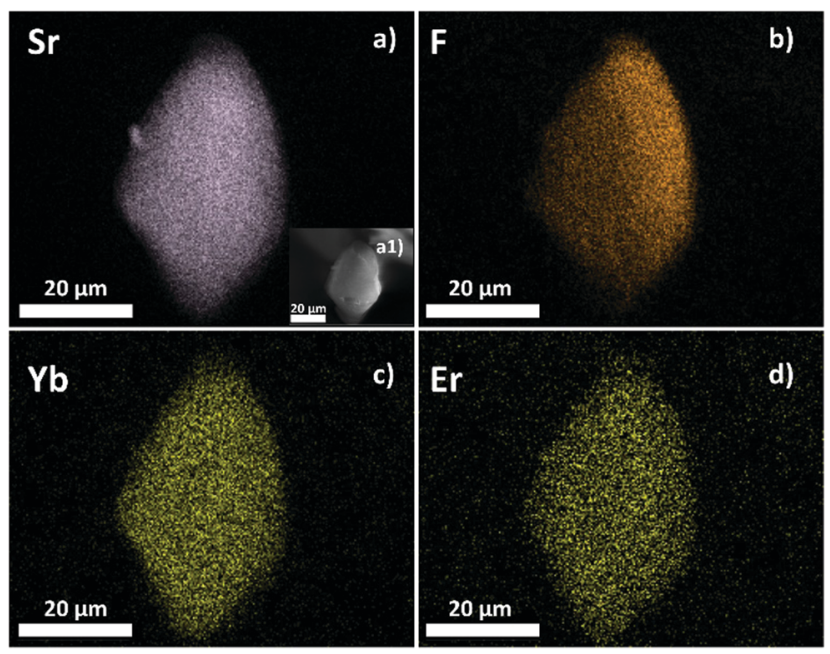

Fig. 2 EDX analysis: SEM images of the fibre cross section with $\mathrm{SrF}_{2}$ $\mathrm{Yb}^{3+}, \mathrm{Er}^{3+} \mathrm{NPs}$, where the SEM image (a1) demonstrates the presence of strontium (a), fluoride (b), ytterbium (c), and erbium (d).

fibres after NIR excitation, characteristic for $\mathrm{Er}^{3+}$ ions. Further, the FM NPs are distributed homogeneously within the cellulose matrix, what is in good agreement with SEM EDS mapping results.

In order to determine the impact of cellulose luminescent fibre additives on the paper structure, the following properties were tested: surface roughness and air permeance. The results are presented in Table 2 and Fig. 4 . The presence of luminescent lyocell fibres resulted in an increase of surface roughness and air permeance, which is beneficial in some applications, e.g. membrane technology. The increase of these parameters is the highest for paper containing $10 \mathrm{wt} \%$ of the lyocell fibres in mass. The surface roughness increased, in this case, by $\sim 1.5$ times and the air permeance by 3 times. Lyocell fibres mixed with paper pulp create a more porous paper structure, which means air can easily penetrate it, and surface roughness increases.

Spectroscopic properties of the obtained fibres, modified with $\mathrm{SrF}_{2}: \mathrm{Yb}^{3+}, \mathrm{Er}^{3+} \mathrm{NPs}$, were analysed based on the upconversion emission spectra and luminescence lifetimes (see ESI $\dagger$ ), recorded at $\lambda_{\text {exc }}=975 \mathrm{~nm}$ (Fig. 5a, and Fig. S4, S5, ESI $\dagger$ ). In this system, $\mathrm{Yb}^{3+}$ ions act as sensitizers (light harvesting ions), effectively absorbing NIR light (see Fig. S4 and S6, ESI $\dagger$ ) and transferring it (via energy transfer upconversion mechanisms) to the emitting $\mathrm{Er}^{3+}$ ions. The spectra, typical for $\mathrm{Er}^{3+}$ ions, show three intense bands centred around 525, 550, and $650 \mathrm{~nm}$, related to the ${ }^{2} \mathrm{H}_{11 / 2} \rightarrow{ }^{4} \mathrm{I}_{15 / 2},{ }^{4} \mathrm{~S}_{3 / 2} \rightarrow{ }^{4} \mathrm{I}_{15 / 2}$, and ${ }^{4} \mathrm{~F}_{9 / 2} \rightarrow{ }^{4} \mathrm{I}_{15 / 2}$ transitions, respectively (Fig. 5a). The calculated chromaticity coordinates, $x=0.191$ and $y=0.565$, were pointed in the yellow-green region (Fig. 5b). The luminescence colour was established as greenish, which can be observed in the photographs, where the modified fibres are irradiated with a laser at $\lambda_{\text {exc }}=975 \mathrm{~nm}$ (Fig. 5b, c and Fig. S3, S7, ESI †). The emission colour of the modified fibres is shifted slightly to the green region compared with the pure modifier, confirming the difference in the relative emission intensity between the bands located in the green spectral region $\left({ }^{2} \mathrm{H}_{11 / 2} \rightarrow{ }^{4} \mathrm{I}_{15 / 2},{ }^{4} \mathrm{~S}_{3 / 2} \rightarrow{ }^{4} \mathrm{I}_{15 / 2}\right)$ and red region

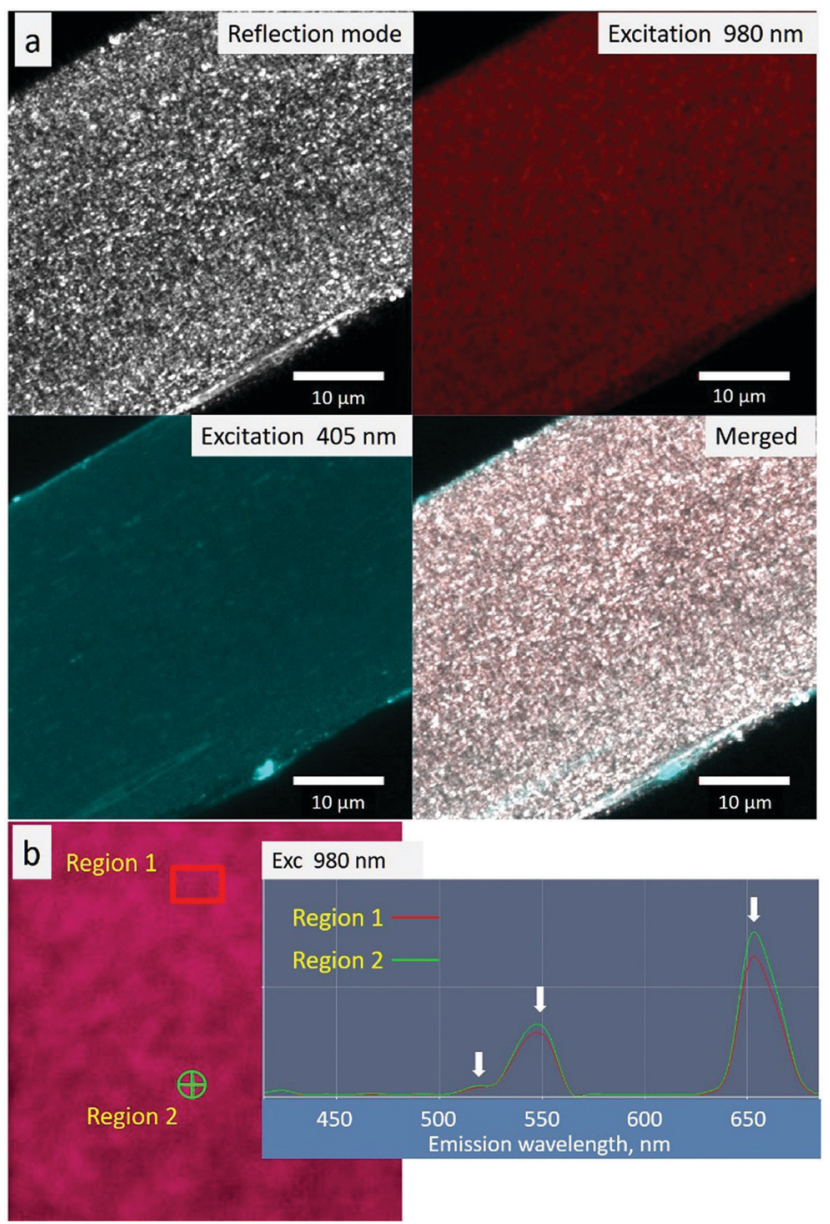

Fig. 3 Luminescence and fluorescence images of a modified fibre taken in reflection mode at excitation wavelengths of 980 and $405 \mathrm{~nm}$ (a), and luminescence spectra of a modified fibre taken at an excitation wavelength of $980 \mathrm{~nm}$ (b).

$\left({ }^{4} \mathrm{~F}_{9 / 2} \rightarrow{ }^{4} \mathrm{I}_{15 / 2}\right)$ for both samples. This is due to several reasons, such as (I) different light scattering on pure NPs compared to modified fibre; (II) reabsorption of emitted light by the fibre; and (III) a difference in power of the incident laser beam, caused by the initially mentioned effects (I and II), which, in the case of non-linear upconversion, may change the shape of the spectrum.

Upconversion of cellulose fibres was used as an additional (invisible, "secret") modifier to paper sheets.

The modification and application of different contents of modified fibres shows that the addition of even $0.5 \mathrm{wt} \%$ fibre is

Table 2 Basic properties of the pure and modified paper samples

\begin{tabular}{lll}
\hline FM [\%] & $\begin{array}{l}\text { Surface roughness } \\
\left(\text { Bendsten) }\left[\mathrm{mL} \mathrm{min}^{-1}\right]\right.\end{array}$ & $\begin{array}{l}\text { Air permeance } \\
(\text { Bendsten })\left[\mathrm{mL} \mathrm{min}^{-1}\right]\end{array}$ \\
\hline 0 & $278 \pm 21$ & $1807 \pm 67$ \\
0.5 & $404 \pm 33$ & $1746 \pm 70$ \\
1 & $395 \pm 49$ & $1772 \pm 41$ \\
3 & $462 \pm 41$ & $2001 \pm 39$ \\
5 & $590 \pm 88$ & $2120 \pm 51$ \\
10 & $836 \pm 68$ & $2648 \pm 94$
\end{tabular}



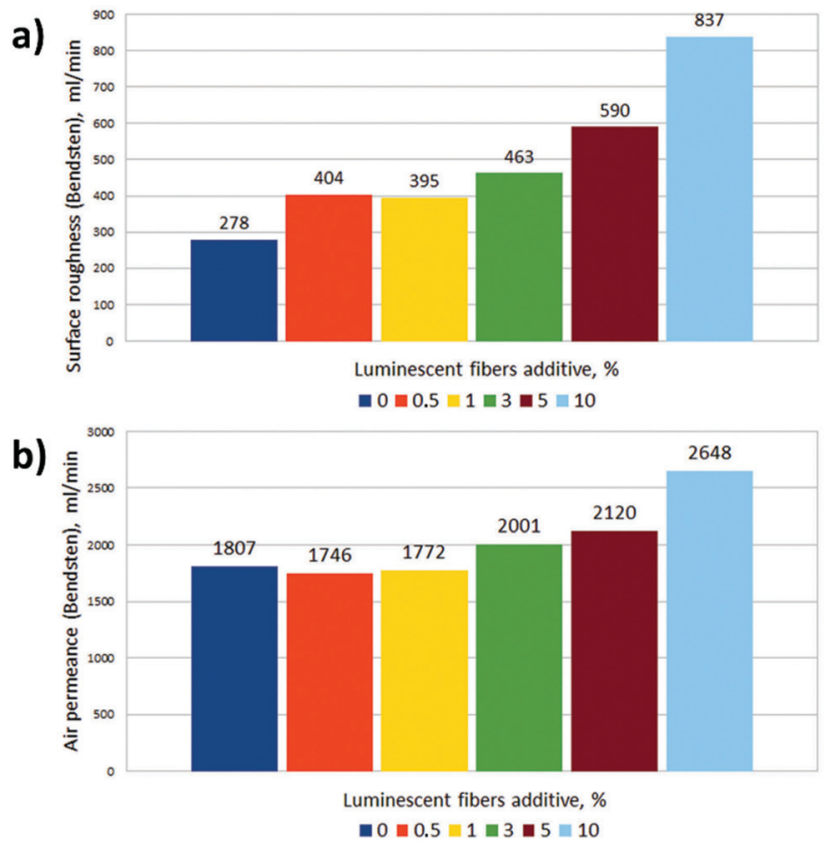

Fig. 4 Basic physical properties of paper samples at different concentrations of luminescent lyocell fibres: (a) surface roughness and (b) air permeance.
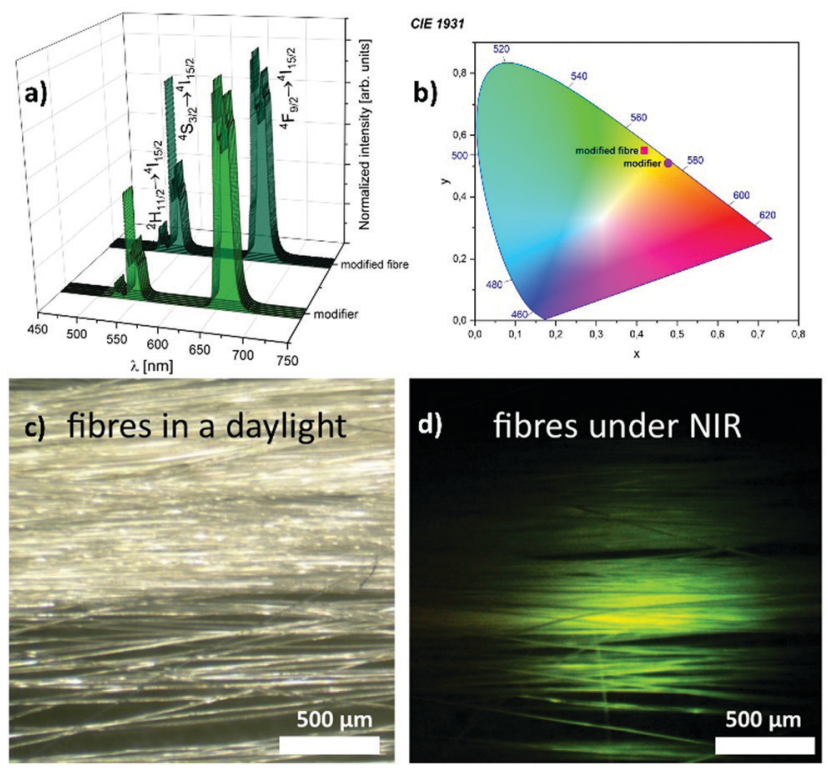

Fig. 5 Upconversion emission spectra of FM and modified fibres (a), a chromaticity diagram presenting the colour of the NPs and modified fibres emission (b), and photographs taken with a CCD camera coupled to an optical microscope at $20 \times$ magnification (c and d).

enough to observe greenish emission in the paper with the naked eye. As expected, as the concentration of upconverting fibres increases, the luminescence properties of the paper are more visible, due to the higher density of fibres in the paper sheet (Fig. 6 and Fig. S7, ESI†).

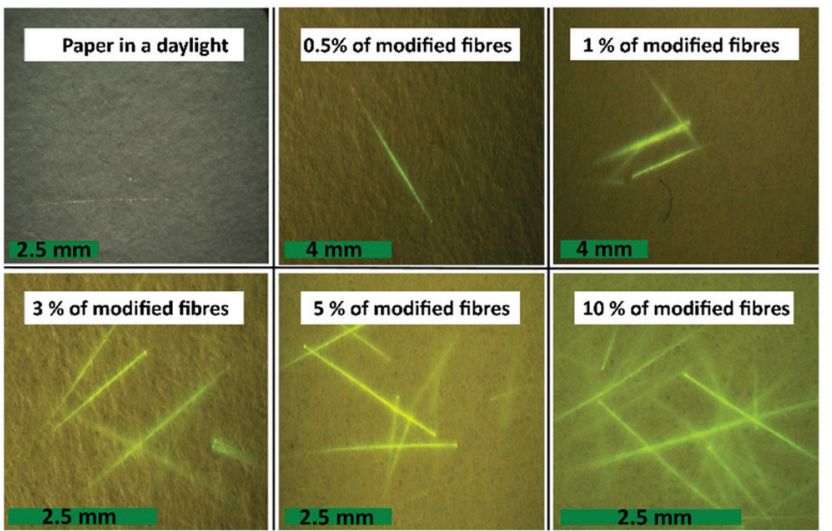

Fig. 6 Photographs of modified paper sheets taken with a CCD camera coupled to an optical microscope.

\section{Conclusions}

We have shown it is possible to obtain upconverting luminescent cellulose fibres functionalized with lanthanide-doped NPs and introduce them into paper pulp in the form of an invisible (in daylight), "secret" modifiers, which can be revealed only under NIR laser irradiation, as bright greenish illumination. The functionalized fibres were obtained by a low-cost, facile, and easy to scale-up NMMO method. The performed SEM and EDX analyses show that the applied upconverting modifier $\left(\mathrm{SrF}_{2}: \mathrm{Yb}^{3+}, \mathrm{Er}^{3+} \mathrm{NPs}\right)$ is evenly distributed in the polymer matrix of cellulose fibres, without any aggregation, and has a good influence on the mechanical properties of the obtained fibres. The FM introduced into the polymer matrix of the fibres promotes the fibre spinning process and results in fibres with very good tenacity, positively influencing their utility properties. The presence of lyocell fibres in the paper structure causes an increase of basic physical parameters of the paper (surface roughness, air permeance), which is associated with differences in the structures of man-made cellulose fibres and natural fibres of paper pulp. This should be an important issue in further studies. The obtained experimental results allow for the development of modern and advanced document protection, performed in a low-cost and facile way.

\section{Conflicts of interest}

There are no conflicts to declare.

\section{Acknowledgements}

The presented results were financially supported by the National Centre for Research and Development, LIDER/39/0141/L-9/17/ NCBR/2018 "Ecological cellulose fibers and paper modified with micro- and nanoluminophores activated with ultraviolet and infrared radiation." Additional acknowledgments to professor Jacek Gapiński, from the NanoBioMedical Centre, and Adam Mickiewicz, University in Poznan, for measurements with a confocal microscope. 


\section{References}

1 A. Guerrero-Martínez, J. Pérez-Juste and L. M. Liz-Marzán, Adv. Mater., 2010, 22, 1182-1195.

2 R. Li, Z. Ji, J. Dong, C. H. Chang, X. Wang, B. Sun, M. Wang, Y.-P. Liao, J. I. Zink, A. E. Nel and T. Xia, ACS Nano, 2015, 9, 3293-3306.

3 E. C. Ximendes, U. Rocha, T. O. Sales, N. Fernández, F. SanzRodríguez, I. R. Martín, C. Jacinto and D. Jaque, Adv. Funct. Mater., 2017, 27, 1702249.

4 M. Runowski, S. Sobczak, J. Marciniak, I. Bukalska, S. Lis and A. Katrusiak, Nanoscale, 2019, 11, 8718-8726.

5 Q. Guo, Q. Wang, L. Jiang, L. Liao, H. Liu and L. Mei, Phys. Chem. Chem. Phys., 2016, 18, 15545-15554.

6 A. Gnach and A. Bednarkiewicz, Nano Today, 2012, 7, 532-563.

7 M. A. Hernández-Rodríguez, A. D. Lozano-Gorrín, I. R. Martín, U. R. Rodríguez-Mendoza and V. Lavín, Sens. Actuators, B, 2018, 255, 970-976.

8 P. Mazierski, W. Lisowski, T. Grzyb, M. J. Winiarski, T. Klimczuk, A. Mikołajczyk, J. Flisikowski, A. Hirsch, A. Kołakowska, T. Puzyn, A. Zaleska-Medynska and J. Nadolna, Appl. Catal., B, 2017, 205, 376-385.

9 X. Ling, R. Shi, J. Zhang, D. Liu, M. Weng, C. Zhang, M. Lu, X. Xie, L. Huang and W. Huang, ACS Sens., 2018, 3, 1683-1689.

10 J. Zhou, J. L. Leaño, Z. Liu, D. Jin, K.-L. Wong, R.-S. Liu and J.-C. G. Bünzli, Small, 2018, 14, 1801882.

11 K. Binnemans, Chem. Rev., 2009, 109, 4283-4374.

12 B. G. Wybourne and L. Smentek, Optical spectroscopy of lanthanides, CRC Press, New York, 2007.

13 J.-C. G. Bünzli, Trends Chem., 2019, 1, 751-762.

14 M. Runowski, Handbook of Nanomaterials in Analytical Chemistry, Elsevier, 2020, pp. 227-273.

15 W. Zheng, P. Huang, D. Tu, E. Ma, H. Zhu and X. Chen, Chem. Soc. Rev., 2015, 44, 1379-1415.

16 S. Ranjan, M. K. G. Jayakumar and Y. Zhang, Nanomedicine, 2015, 10, 1477-1491.

17 Q. Guo, C. Zhao, Z. Jiang, L. Liao, H. Liu, D. Yang and L. Mei, Dyes Pigm., 2017, 139, 361-371.

18 A. Szczeszak, A. Ekner-Grzyb, M. Runowski, K. Szutkowski, L. Mrówczyńska, Z. Kaźmierczak, T. Grzyb, K. Dąbrowska, M. Giersig and S. Lis, J. Colloid Interface Sci., 2016, 481, 245-255.

19 G.-L. Law, K.-L. Wong, H.-L. Tam, K.-W. Cheah and W.-T. Wong, Inorg. Chem., 2009, 48, 10492-10494.
20 C. D. S. Brites, K. Fiaczyk, J. F. C. B. Ramalho, M. Sójka, L. D. Carlos and E. Zych, Adv. Opt. Mater., 2018, 6, 1701318. 21 F. Auzel, C. R. Acad. Sci. Paris B, 1966, 263, 819-821.

22 A. Nadort, J. Zhao and E. M. Goldys, Nanoscale, 2016, 8, 13099-13130.

23 A. Bartkowiak, A. Siejca, K. Borkowski, S. Lis and T. Grzyb, J. Alloys Compd., 2019, 784, 641-652.

24 J.-C. G. Bünzli, Eur. J. Inorg. Chem., 2017, 5058-5063.

25 M. Skwierczyńska, M. Runowski, S. Goderski, J. Szczytko, J. Rybusiński, P. Kulpiński and S. Lis, ACS Omega, 2018, 3, 10383-10390.

26 H. Huang, J. Chen, Y. Liu, J. Lin, S. Wang, F. Huang and D. Chen, Small, 2020, 16, 1-12.

27 J. Lin, C. Yang, P. Huang, S. Wang, M. Liu, N. Jiang and D. Chen, Chem. Eng. J., 2020, 395, 125214.

28 S. Wang, J. Chen, J. Lin, C. Yang, F. Huang and D. Chen, J. Mater. Chem. C, 2019, 7, 14571-14580.

29 J. Chen, S. Wang, J. Lin and D. Chen, Nanoscale, 2019, 11, 22359-22368.

30 A. Erdman, P. Kulpinski, T. Grzyb and S. Lis, J. Lumin., 2016, 169, 520-527.

31 X. Li, C. Qian, R. Shen, H. Xiao, W. Zhao and S. Ye, Opt. Express, 2018, 26, 30753.

32 Z. Mo, H. Guo, Y. Wang, H. Yin, C. Yang and J. Song, J. Alloys Compd., 2017, 695, 2525-2531.

33 Y. Shi and B. Wang, Prog. Nat. Sci.: Mater. Int., 2014, 24, 56-60.

34 Z. Chang, S. Li, L. Sun, C. Ding, X. An and X. Qian, Cellulose, 2019, 26, 6739-6754.

35 J. Grob and K. Franken, EP1479797A1, 2004.

36 D. K. Choi, C. H. Kil and Y. J. Jang, EP2156963A1, 2010.

37 A. Erdman, P. Kulpinski and K. Olejnik, Cellulose, 2016, 23, 2087-2097.

38 A. Erdman, T. Grzyb, P. Kulpinski, J. Lazarek, S. Lis, K. Olejnik, M. Reczulski, P. S. Szczepaniak and A. Wysocka-Robak, Fibres Text. East. Eur., 2016, 24, 107-112.

39 D. Przybylska, A. Ekner-Grzyb, B. F. Grześkowiak and T. Grzyb, Sci. Rep., 2019, 9, 1-12.

40 E. Smiechowicz, P. Kulpinski, B. Niekraszewicz and A. Bacciarelli, Cellulose, 2011, 18, 975-985.

41 M. Skwierczyńska, M. Runowski, P. Kulpiński and S. Lis, Carbohydr. Polym., 2019, 206, 742-748.

42 A. C. Croce and G. Bottiroli, Eur. J. Histochem., 2014, 58, 320-337. 